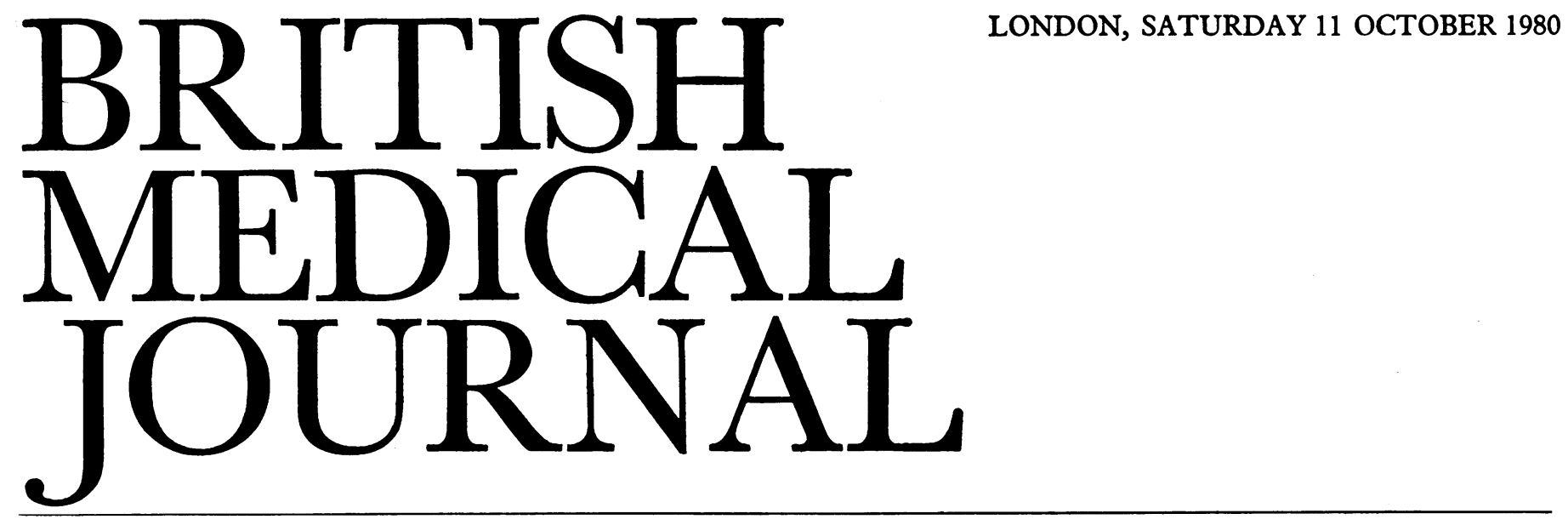

\title{
Vitamin A, retinol, carotene, and cancer prevention
}

Recent evidence ${ }^{1}$ suggests that up to half of all cancers may be related to diet, making the combined effects of food and drink a more important determinant of the risk of cancer than smoking. ${ }^{2}$ The strong association between total fat intake and the incidence of breast and colonic cancer ${ }^{2}$ and the evidence from laboratory experiments ${ }^{3}$ that small reductions of energy intake can dramatically reduce the total incidence of tumours in animals are two important components of the relation between cancer and diet. A third, on which much evidence has been accumulating, is the association of vitamin $\mathrm{A}$ with cancer.

More than three-quarters of the vitamin A in the British diet comes preformed as retinol or its esters from liver, dairy products, or vitamin pills. The remainder comes directly from carrots or green leafy vegetables which yield carotene or other carotenoids, which can be split into vitamin $\mathrm{A}$ in the intestine. Elsewhere, and in particular in West African countries where palm oil is used, vegetable products can be the main source of vitamin $A$.

Vitamin A is well known to be important in the general growth and differentiation of epithelial tissues. In animals deficiency of vitamin A has been shown to enhance susceptibility to various chemical carcinogens in the respiratory tract, bladder, colon, and stomach. ${ }^{45}$ Whether high doses of natural retinoids can inhibit the development, or slow the growth, of cancers in laboratory animals maintained on adequate diets is less clear. In most studies on such animals natural retinoids have been found to inhibit or even cause regression of tumours induced by chemicals or viruses. In contrast, however, transplanted tumours generally do not respond. Furthermore, in a few instances retinoids have been found to enhance the growth of tumours induced by chemicals. ${ }^{5}$ Reviewing this apparently conflicting evidence, Sporn et $a l^{4}$ concluded that in some circumstances natural retinoids could prevent the development of epithelial cancer but that they were of limited use as agents for chemoprevention owing either to inadequate distribution in the tissues or to excessive toxicity, or to both.

In man, retinoic acid applied topically has been shown to cause regression of actinic keratoses and basal-cell carcinomas, and when given by mouth it has been associated with regression of papillomas of the urinary bladder and leukoplakia of the mouth, tongue, and larynx." Nevertheless, high doses of retinoids are known to produce hypervitaminosis $\mathrm{A}-$ characterised by changes in the skin and mucous membranes, liver dysfunction, and headache-which has tended to limit their systemic use in clinical practice. Research has therefore been aimed at developing a synthetic retinoid which would maximise the antitumour effect while keeping toxicity to a minimum. Over 1000 retinoids have already been tested, with only partial success. ${ }^{5}$

Five years ago, in a dietary prospective study of over 8000 Norwegian men, Bjelke and his colleagues ${ }^{6}$ found an inverse association between the incidence of lung cancer and an index of dietary vitamin A based mainly on vegetable sources. This led to a wave of epidemiological interest in vitamin $\mathrm{A}$; but only one other relevant prospective study has so far been reported. Hirayama ${ }^{7}$ observed 807 lung cancers among over a quarter of a million Japanese who had been asked about their diets in 1965. He found that the risk of lung cancer was reduced by half in those who ate green or yellow vegetables "daily" as compared with those who ate them less frequently. Case-control studies of diet are generally thought less reliable (especially for gastrointestinal cancers in which appetite is often affected) because memory of past dietary habits is known to be poor; nevertheless, an impressive list of such studies supports the negative relation between vitamin $A$ and cancer. Two studies showed a decreased use of vitamin A pills in patients with lung cancer, ${ }^{8} 9$ six studies showed a decreased intake of sources of carotene in patients with bladder, lung, stomach, or colorectal cancer, ${ }^{10-15}$ and one showed a lower consumption of liver in men (though not women) with lung cancer. ${ }^{9}$

In general, this negative association is not very strong, with less than a doubling of risk in the groups with a low intake of vitamin A. This association, however, may be consistently underestimated because of inaccuracy in measuring dietary variables. In one small prospective study, ${ }^{16}$ in which blood samples were taken from healthy individuals, Kark et al found that those with low retinol values had a sixfold increased risk of later developing cancer. Low serum concentrations of retinoids have also been found retrospectively in patients with lung cancer in England ${ }^{17}$ and in patients with oral cancer in Pakistan $^{18}$ and India, ${ }^{19}$ though these low values might conceivably have been a result of the cancers rather than their cause.

Even if serum concentrations of retinol do prove to be an important determinant of risk in human cancer, the association will be complicated by the fact that large increases in the intake of vitamin A cause only a small increase in these concentrations $^{20}$ (except where frank deficiency is common ${ }^{21}$ ). Peto et $a l^{22}$ have suggested that attempts to increase serum concentrations of carotene may prove to be more useful. They point 
out that experiments on animals have shown that carotene also has a cancer-reducing effect, and that most of the epidemiological data are as relevant for carotene as they are for retinol. In the studies of oral cancer ${ }^{1819}$ in India and Pakistan lower serum concentrations of carotene as well as of retinol were observed in the cases than in the controls. As the amount of carotene eaten increases the proportion converted to vitamin A decreases and the serum concentration of carotene rises steadily. A grant application is currently being considered in the United States of America by the National Heart, Lung and Blood Institute and National Cancer Institute for a randomised controlled trial of carotene on 25000 doctors (R Peto, personal communication).

${ }^{1}$ Miller AB. Nutrition and cancer. Prev Med 1980;9:189-96.

2 Gori GB. Dietary and nutritional implications in the multifactorial etiology of certain prevalent human cancers. Cancer 1979;43:2151-61.

${ }^{3}$ Roe FJ. Food and cancer. F Hum Nutr 1979;33:405-15.

4 Sporn MB, Dunlop NM, Newton DL, Smith JM. Prevention of chemical carcinogenesis by vitamin $\mathrm{A}$ and its synthetic analogs (retinoids). Fed Proc 1976;35:1332-8.

5 Bollag W. Retinoids and cancer. Cancer Chemotherapy and Pharmacology $1979 ; 3: 207-16$.

${ }^{6}$ Bjelke E. Dietary vitamin A and human lung cancer. Int $\mathcal{F}$ Cancer 1975; $15: 561-5$.

${ }^{7}$ Hirayama T. Diet and cancer. Nutrition and Cancer 1979;1(3):67-81.

${ }^{8}$ Smith PG, Jick H. Cancers among users of preparations containing vitamin A: a case-control investigation. Cancer 1978;42:808-11.

${ }^{9}$ Gregor A, Lee PN, Roe FJC, Wilson MJ, Melton A. Nutrition and Cancer (in press).

${ }^{10}$ Mettlin C, Graham S. Dietary risk factors in human bladder cancer. $A m \mathcal{F}$ Epidemiol 1979;110:255-63.

${ }^{11}$ Maclennan R, Da Costa J, Day NE, Law CH, Ng YK, Shanmugaratnam K. Risk factors for lung cancer in Singapore Chinese, a population with high female incidence rates. Int $\mathcal{F}$ Cancer 1977;20:854-60.

12 Mettlin C, Graham S, Swanson M. Vitamin A and lung cancer. $\mathcal{F} \mathrm{Natl}$ Cancer Inst 1979;62:1435-8.

${ }^{13}$ Bjelke E. In: Aktuelle probleme der klinischen diatetik. Suppl zu Aktuelle ernährungsmedizin. Stuttgart: George Thieme, 1978:10-7.

14 Stocks P. Cancer incidence in North Wales and Liverpool region in relation to habits and environment. British Empire Cancer Campaign Thirty-Fifth Annual Report (suppl to part II) 1957;1-156.

${ }^{15}$ Phillips RL. Role of life-style and dietary habits in risk of cancer among Seventh-Day Adventists. Cancer Res 1975;35:3513-22.

${ }^{16}$ Kark JD, Smith AH, Hames CG. F Chronic Dis (in press).

17 Atukorala S, Basu TK, Dickerson JWT, Donaldson D, Sakula A. Vitamin $A$, zinc and lung cancer. $B r \mathcal{F}$ Cancer $1979 ; 40: 927-31$.

18 Ibrahim $K$, Jafarey NA, Zuberi SJ. Plasma vitamin ' $A$ ' and carotene levels in squamous cell carcinoma of oral cavity and oro-pharynx. Clin Oncol $1977 ; 3: 203-7$.

19 Wahi PN, Bodkhe RR, Agora S, Srivastava MC. Serum vitamin A studies in leukoplakia and carcinoma of the oral cavity. Indian fournal of Pathology and Bacteriology 1962;5:10-6.

20 Vahlquist A, Michaëlsson G, Juhlin L. Acne treatment with oral zinc and vitamin A: effects on the serum levels of zinc and retinol binding protein (RBP). Acta Derm Venereol (Stockh) 1978;58:437-42.

21 Patwardhan VN. Hypovitaminosis A and epidemiology of xerophthalmia. Am $\mathcal{F}$ Clin Nutr 1969 ;22:1106-18.

${ }^{22}$ Peto R, Doll R, Buckley JD, Sporn MB. Nature (in press).

\section{Aspirin sensitivity in asthmatics}

Asthmatic patients sensitive to aspirin develop dramatically increased airways obstruction after taking the drug. Severe wheezing is accompanied by profuse rhinorrhoea and sometimes by facial flushing and urticaria; occasionally it is also followed by abdominal colic, vomiting, or diarrhoea.

Idiosyncrasy of response to aspirin was noted soon after its commercial introduction in 1899, ${ }^{1}$ and, generally, patients with this condition have symptoms that follow a well-recognised pattern. ${ }^{2}$ Intermittent rhinorrhoea develops in the second or third decade of life; this then becomes continuous and severe, often leading to recurrent nasal polypi. During the next few years asthma develops, to be followed in the mid-30s by sensitivity to aspirin - which the patient could previously take with impunity. The condition occurs more commonly in women, and generally there is no evidence of sensitivity to other extrinsic allergens. It may, however, occur in atopic people and it is not unknown in children. ${ }^{3}$ Similar asthmatic reactions can be produced by other analgesics ${ }^{4}$-including indomethacin, ibuprofen, mefenamic acid, phenylbutazone, dextropropoxyphene, paracetamol, and pentazocine-and by tartrazine, ${ }^{2}$ an orange-yellow azo dye used to colour foods, soft drinks, and drugs, though individuals developing reactions to aspirin do not necessarily react to these other agents.

From $0 \cdot 2 \%{ }^{5}$ to $20 \%{ }^{6}$ of asthmatic patients are estimated to be sensitive to aspirin. In the only British survey ${ }^{7} \%$ of 1205 patients attending an asthma clinic were sensitive to it. Surveys based on challenge testing with aspirin, however, generally give higher figures-varying from $13 \%$ in a paediatric study ${ }^{8}$ to $19 \%$ in a recent adult study. ${ }^{9}$ Indeed, although a history of aspirin idiosyncrasy is usually reliable, in the absence of an in-vitro test the only way to confirm the diagnosis is by challenge testing by mouth. This is not hazardous if undertaken in hospital under medical supervision, using incremental doses of aspirin while the patient is observed for evidence of increased airways obstruction. ${ }^{910}$ The threshold for patients with an unequivocal history appears to be low, and very small doses of aspirin (for example, $30 \mathrm{mg}$ ) or even paracetamol will produce a reaction; whereas patients with a negative history normally require larger doses of aspirin (for example, $300 \mathrm{mg}$ ) to produce changes in lung function. ${ }^{11}$

The analgesic drugs most commonly causing increased airways obstruction are known to be inhibitors of prostaglandin synthetase, and the severity of the reactions they produce appears to be directly proportional to their activity as inhibitors of this enzyme. ${ }^{12}$ Measurements of serum prostaglandins $E_{2}$ and $F_{2 \alpha}$ concentrations during aspirin-induced asthmatic attacks showed only trace amounts, but such measurements are probably a poor indicator of prostaglandin activity in the relevant tissues. ${ }^{13}$ When prostaglandin synthesis in passively sensitised human lung is suppressed by indomethacin, the release of slow-reacting substance of anaphylaxis (SRS-A) is appreciably enhanced. ${ }^{14}$ SRS-A is a powerful bronchoconstrictor, and its release may account for the severe airways obstruction after taking analgesics. Time-course measurements of plasma concentrations of prostaglandins and SRS-A during analgesic-induced asthmatic attacks should provide valuable information on this point.

Aspirin-sensitive asthmatics must be warned to avoid all aspirin-containing drugs and to treat with caution all other analgesics. Before an analgesic is pronounced safe the patient should ideally be challenge-tested with it under hospital surveillance. Although tartrazine is less likely to cause problems, the doctor should be careful when prescribing yellow-orange coloured drugs that may contain the dye-which is used in some antihistamines, antibiotics, and bronchodilators commonly used by asthmatic patients. ${ }^{15}$

${ }^{1}$ Hirschberg (Posen). Mittheilung über einen Fall von Nebenwirkung des Aspirin. Dtsch Med Wochenschr 1902 ;28, suppl:416.

2 Samter M, Beers RF. Intolerance to aspirin. Clinical studies and consideration of its pathogenesis. Ann Intern Med 1968;68:975-83.

${ }^{3}$ Falliers CJ. Aspirin and subtypes of asthma: risk factor analysis. $\mathcal{f}$ Allergy Clin Immunol 1973;52:141-7.

${ }^{4}$ Smith AP. Response of aspirin-allergic patients to challenge by some analgesics in common use. $\mathrm{Br} \mathrm{Med} \mathcal{F} 1971$;ii:494-6.

${ }^{5}$ Gardner E, Blanton WB. The incidence of aspirin hypersensitivity. $A m \mathcal{F}$ Med Sci 1940;200:390-4.

${ }^{6}$ Farr RS. The need to re-evaluate acetylsalicylic acid (aspirin). Fournal of Allergy 1970;45:321-8. 